\title{
The use of scrotal ultrasound in the evaluation of varicoceles: A survey study of reproductive specialists
}

Jabez C. Gondokusumo1; Mohit Butaney²; Adithya Balasubramanian'; Jonathan A. Beilan"; Alexander J. Tatem ${ }^{1}$; Nannan Thirumavalavan ${ }^{3}$; Alexander W. Pastuszak ${ }^{4}$; Larry I. Lipshultz ${ }^{1}$ ${ }^{1}$ Scott Department of Urology, Baylor College of Medicine, Houston, TX, United States; ${ }^{2}$ Department of Urology, Mayo Clinic, Rochester, MN, United States; ${ }^{3}$ University Hospitals Urology Institute Case Western Reserve University, Cleveland, OH, United States; ${ }^{4}$ Division of Urology, Department of Surgery, University of Utah School of Medicine, Salt Lake City, UT, United States

Funding/Acknowledgements: This work is supported in part by NIH grant K12 DK0083014, the Multidisciplinary K12 Urologic Research (KURe) Career Development Program (NT is a K12 Scholar). A.W.P. is a National Institutes of Health K08 Scholar supported by a Mentored Career Development Award (K08DK115835-01) from the from the National Institute of Diabetes and Digestive and Kidney Diseases. This work is also supported in part through a Urology Care Foundation Rising Stars in Urology Award (to A.W.P.)

Cite as: Can Urol Assoc J 2020 March 23; Epub ahead of print. http://dx.doi.org/10.5489/cuaj.6147

Published online March 23, 2020

$* * *$

\section{Abstract}

Introduction: Urologists use ultrasound in the male infertility workup to evaluate scrotal contents and objectively identify varicoceles if their presence is questionable on physical examination. We assessed practice patterns and diagnostic criteria of male reproductive urologists using ultrasound to evaluate varicoceles.

Methods: An anonymous online survey was sent to the Society for Male Reproduction and Urology (SMRU) members. We queried respondents about ultrasonographic criteria and ultrasound techniques employed in varicocele evaluation. Chi-squared was used to determine association between categorical variables.

Results: In total, 110/320 (34.4\%) SMRU members responded. Sixty percent of respondents (66/110) reported performing scrotal ultrasound; $92.4 \%(61 / 66)$ were attending urologists and $87.9 \%$ (58/66) completed an andrology fellowship. A total of 37.9\% (25/66) performed their own ultrasound, while the remainder had ultrasound performed by an alternate practitioner. Among those performing their own ultrasound, 95.5\% (21/22) measured varicocele venous diameter compared to $76 \%$ (29/38) when another practitioner performed the ultrasound. Venous diameter 
used to define a varicocele ranged from 2-4 mm. Although 80\% (49/61) of respondents assessed retrograde flow during ultrasound, only $52.5 \%$ reported that retrograde flow was required for varicocele diagnosis. Almost all (60/61) indicated that they would fix palpable varicoceles in patients with abnormal semen parameters. Fewer $(42.6 \%, 26 / 61)$ respondents stated they would repair varicoceles found exclusively on ultrasound.

Conclusions: Ultrasound is commonly employed by male reproductive urologists to diagnose varicoceles. We identified that practitioners use various ultrasonographic criteria and techniques for varicocele diagnosis. Study limitations include recall bias and high degree of specialization among respondents.

\section{Introduction}

Scrotal varicoceles, representing retrograde flow into the internal spermatic vein and results in abnormal dilatations of the pampiniform plexus. This aberrant venous flow can contribute to abnormal semen analysis parameters, such as reduced sperm density, decreased motility, abnormal semen morphology, and increased DNA damage ${ }^{2,1,3}$. While varicoceles are present in approximately $15 \%$ of all males, more than $40 \%$ of infertile men present with this abnormality. ${ }^{1}$.

The current diagnosis of varicocele requires palpation of the scrotum with the patient standing in a warm room ${ }^{3}$. Ultrasound has also been utilized for detection and diagnosis of varicoceles, particularly those that are not palpable due to thick scrotal skin, a high scrotum or after previous attempted varicocele repair, or "subclinical" (i.e., not easily appreciated on physical examination alone). Evidence suggests that patients with subclinical varicoceles may benefit from microsurgical repair, but controlled studies have been few and the results controversial ${ }^{4}$. Microsurgical varicocele repair is one of the most common procedures performed for treatment of male infertility, but identifying who benefits most from this intervention remains a challenge. The impact of subclinical varicocele repair on improving fertility remains undetermined with more data required to draw valid conclusions ${ }^{5,6}$. Similar to the variability encountered with physical exam alone and given the lack of specific ultrasound guidelines, we hypothesize that the diagnosis of varicoceles using ultrasound is highly provider dependent, and could contribute to the conflicting results in provider treatment algorithms and studies examining outcomes of varicocele repair. In this study, we assess the various approaches to the ultrasonographic diagnosis of varicoceles as reported by a cohort of practitioners in male reproductive medicine. 


\section{Methods}

After obtaining Institutional Review Board approval, a 30-question anonymous web-based survey was designed and electronically deployed through Survey Monkey (San Mateo, California, USA) to members of the Society for Male Reproduction and Urology (SMRU). This survey assessed current practice patterns of scrotal ultrasonography, including techniques and interpretation. After respondents provided consent, they received the questionnaire and were asked questions regarding their demographics, including practice location and type, years in practice, and training background. Respondents were also asked about their clinical practice regarding the use of scrotal ultrasound for the evaluation of varicoceles. Key questions included: 1) what are the diagnostic requirements for a radiographic diagnosis of varicocele (vein diameter measurement)?; 2) What are the common procedural techniques performed (standing vs supine, Valsalva)?; 3) What are the indications for surgical intervention? The entire content of the survey is available as Supplementary Figure 1.

The survey was sent to members of the SMRU on three separate occasions to maximize response rate. The survey was kept open for 2 months, and incomplete surveys were excluded. Using SurveyMonkey allowed us to customize our survey response collector. One important feature of this program is the automated ability to prevent multiple responses from the same IP address, which allowed us to ensure that no duplicate surveys were collected. Our results were partitioned into respondents who performed their own ultrasound and respondents who read or utilized ultrasound but did not perform the study themselves. Descriptive analyses were used to report overall respondent demographics, venous diameter used to define varicoceles, differences in technique, and indications for varicocele repair.

\section{Results}

Of the 320 SMRU members to whom the survey was distributed, 110 (34.4\%) completed the survey. Of the respondents, $60.0 \%$ (66/110) performed or interpreted scrotal ultrasounds in their routine practice and formed the cohort we utilized for our primary investigation. Most respondents were attending urologists $(92.4 \%, 61 / 66)$, practicing in an urban setting $(71.2 \%$, 47/66) in North America $(92.4 \%, 61 / 66)$. The majority $(87.9 \%, 58 / 66)$ were fellowship-trained in andrology, sexual medicine, or male infertility. Complete respondent demographics are shown in Table 1. Although all respondents read or utilized ultrasounds in their practice, only $37.9 \%$ $(25 / 66)$ of respondents indicated that they performed their own scrotal ultrasounds, while the remainder had either the radiology department or a technician perform the study.

Of respondents who performed their own ultrasound, $88.0 \%(22 / 25)$ routinely looked for varicoceles. Of these respondents, most $(95.5 \%, 21 / 22)$ used a high scrotal probe position to assess the scrotal veins, and routinely measured the venous diameters $(95.5 \%, 21 / 22)$. As seen in Table 2, a high degree of variability was found in the definition of a varicocele, with reported diagnostic diameters ranging between 2 and 4 millimeters $(\mathrm{mm})$; however, $3 \mathrm{~mm}$ seemed to be a 
common threshold used by many respondents $(39.4 \%, 26 / 66)$. All respondents measured the venous diameter and checked for varicoceles in the supine position $(100.0 \%, 22 / 22)$ while an additional 54.5\% (12/22) made a standing measurement as well. Additionally, 95.5\% (21/22) assessed for the presence of retrograde flow in dilated veins, but only $72.7 \%(16 / 22)$ required this for a radiographic diagnosis of varicocele. All respondents $(100.0 \%, 22 / 22)$ had their patients Valsalva while making measurements.

A total of 41 practitioners exclusively read or utilized scrotal ultrasound but did not perform the study themselves. Of these, three did not complete the survey. Of those that completed the survey, $5.3 \%(2 / 38)$ were unsure if the individual performing the ultrasound looked for varicoceles; $10.5 \%$ (4/38) were unsure whether venous diameters were measured; $26.3 \%(10 / 38)$ were unsure of patient position, and 31.6\% (12/38), were unsure of the ultrasound probe location when measuring scrotal veins. As expected, very few respondents who performed their own US were unaware of these parameters (Table 3). Additionally, a larger proportion of respondents who exclusively only read the ultrasound did not believe retrograde flow was assessed--23.7\%, (9/38) vs 16.0\%, (4/25) in the group that performed their own ultrasound. Furthermore, retrograde flow was a requirement to make a radiographic diagnosis of a varicocele $60.5 \%(23 / 38)$ vs. $36 \%(9 / 25)$ in the group that performed their own ultrasound vs. respondents who did not perform their own study.

Fewer respondents would fix a subclinical varicocele (non-palpable) compared to a clinical (palpable) one (Table 4). Only 78.7\% (48/61), 24.6\% (15/61), 24.6\% (15/61), 41.0\% $(25 / 61)$ and $54.1 \%(33 / 61)$ would fix a palpable varicocele for an indication of pain, hypogonadism, cosmetics, idiopathic infertility, or testicular atrophy, respectively. However, almost all respondents $(98.4 \%, 60 / 61)$ would fix a palpable varicocele with abnormal semen parameters. This was also the most commonly cited indication to repair a subclinical varicocele $(42.6 \%, 26 / 61)$. Of these respondents, $54.1 \%$ (33/61) would not consider repairing a subclinical varicocele for any of the other indications mentioned.

\section{Discussion}

The present work supports the hypothesis that providers diagnosing varicoceles on ultrasound are not using uniform criteria. Using ultrasonography for varicocele diagnosis is not a new concept. Metin et al. compared palpation versus scrotal ultrasonography and found practitioners were able to palpate $100 \%$ of varicoceles in the 5 to 6 millimeter $(\mathrm{mm})$ range, $50 \%$ in the 3 to $4 \mathrm{~mm}$ range, and $16 \%$ in the 1 to $2 \mathrm{~mm}$ range ${ }^{7}$. In ultrasounds of 545 infertile men to detect intra-scrotal abnormalities, 313 left-sided varicoceles were identified via ultrasound, but only $58.3 \%$ $(218 / 313)$ of these were undetected on physical examination ${ }^{8}$. The potential for ultrasound to more accurately diagnose varicoceles in this setting motivated us to investigate practice patterns, techniques, and interpretations of this modality. 
Although scrotal ultrasound can increase varicocele diagnosis, there are variations in 'optimal' ultrasonographic definitions of a varicocele. For example, Eskew et al. concluded that the cut-off diameter measurements for clinical and subclinical varicoceles should be $3.6 \mathrm{~mm}$ and $2.7 \mathrm{~mm}$, respectively, as these were the thresholds that most completely eliminate false positives and negatives ${ }^{9}$. Pilatz et al. conducted a larger study with 217 subjects and concluded that threshold vein diameter measurements of $2.45 \mathrm{~mm}$ when resting and $2.95 \mathrm{~mm}$ during Valsalva were optimal for subclinical varicocele detection ${ }^{10}$. Results from the present study observed that healthcare practitioners utilize measurements ranging from 2 to $4 \mathrm{~mm}$, reiterating the need for standardization.

The physical maneuvers utilized to diagnose varicoceles via ultrasound also varied among respondents. The radiology literature recommends that patients first be assessed in the supine position, with a goal of identifying at least two or three enlarged veins in the pampiniform plexus ${ }^{11}$. Radiologists also recommend that patients perform a Valsalva maneuver to distend veins to enable better visualization on ultrasound ${ }^{11}$. These recommendations also describe that some varicoceles are only apparent in the standing position, and therefore emphasize the need to evaluate patients erect after waiting several minutes to allow the veins to refill ${ }^{11}$.

Lastly, the detection of reflux is recognized as a significant feature of a varicocele. The majority of respondents $(95.2 \%, 60 / 63)$ in our survey require patients to perform Valsalva during ultrasound examination. Despite this overlap with radiologic recommendations, we identified several differences in the ultrasonographic diagnosis of varicocele undertaken by survey respondents. While all respondents performed ultrasound assessment in the supine position, only $42.9 \%(27 / 63)$ routinely evaluated patients in the standing position, and only $49.2 \%(31 / 63)$ required retrograde flow as a criterion when diagnosing varicoceles. As venous reflux and increased heat from venous insufficiency belie the mechanism by which varicoceles impair fertility, a true varicocele should exhibit detectable retrograde flow on ultrasound ${ }^{12,13}$. Overall, these deviations from recommended protocols highlight the need to standardize the ultrasonographic assessment of varicoceles.

The American Urological Association (AUA), American Society for Reproductive Medicine (ASRM), and European Association of Urology (EAU) all state that clinical, palpable varicoceles are associated with infertility, and thereby warrant surgical intervention when semen parameters are abnormal ${ }^{14,15,16}$. Guidelines currently, however, do not recommend surgical correction for subclinical varicocele, whereas $42.6 \%$ (26/61) of survey respondents treat subclinical varicoceles in the setting of infertility and abnormal semen parameters. Surgical correction of subclinical varicoceles remains controversial, as well-designed, prospective, randomized controlled trials are lacking and previous publications have shown non-uniform results $5,6,17-19$. However, the heterogeneity in outcomes may stem from variability in diagnostic criteria utilized, a conclusion supported by the present study's findings. Standardizing diagnostic 
maneuvers and criteria for ultrasonographic varicocele diagnosis can facilitate more rigorous diagnosis, and therefore more accurate assessment of the efficacy of varicocele repair.

Our study has several limitations that warrant further discussion. First, we utilized an anonymous self-reported survey to aggregate data. Studies employing this methodology suffer from varying degrees of recall bias, which may be more pronounced in respondents who are further out from residency or fellowship training. Second, our response rate was $34.4 \%$ $(110 / 320)$. While a higher number of responses would be desirable, this rate is consistent with other studies employing anonymous online surveys ${ }^{20,21}$. Third, the respondents to our survey were members of a professional academic society focused on male infertility. Consequently, respondents to this survey are more likely to be utilizing the latest and most updated clinical guidelines. The high degree of specialization and expertise among our respondents thereby tempers the generalizability of our findings to other practice settings. Despite these limitations, we believe this study provides valuable insight into the variability of scrotal ultrasound practice patterns and highlights a need for standardization in the field with regards to diagnostic criteria associated with varicocele evaluation.

\section{Conclusions}

Despite the popularity of ultrasound among male reproductive specialists, we identified that practitioners employ a wide range of ultrasonographic criteria and techniques for diagnosing varicoceles. Future research should focus on standardizing the ultrasonographic definition and maneuvers utilized to diagnose varicoceles using ultrasound. A more rigorous definition of varicoceles and greater uniformity in diagnostic criteria can potentially better identify male infertility patients who are more likely to benefit from surgical intervention, leading to optimized outcomes. 


\section{References}

1. Inci K, Gunay L. The role of varicocele treatment in the management of non-obstructive azoospermia. Clinics. 2013;

2. Khera M, Lipshultz LI. Evolving Approach to the Varicocele. Urologic Clinics of North America. 2008.

3. Kantartzi PD, Goulis CD, Goulis GD, Papadimas I. Male infertility and varicocele: Myths and reality. Hippokratia. 2007.

4. Pierik FH, Vreeburg JT, Stijnen T, van Roijen JH, Dohle GR, Laméris JS, et al. Improvement of sperm count and motility after ligation of varicoceles detected with colour Doppler ultrasonography. Int J Androl. 1998 Oct;21(5):256-60.

5. Thirumavalavan N, Scovell JM, Balasubramanian A, Kohn TP, Ji B, Hasan A, et al. The Impact of Microsurgical Repair of Subclinical and Clinical Varicoceles on Total Motile Sperm Count: Is There a Difference? Urology. 2018;

6. Kim HJ, Seo JT, Kim KJ, Ahn H, Jeong JY, Kim JH, et al. Clinical significance of subclinical varicocelectomy in male infertility: systematic review and meta-analysis. Andrologia. 2016.

7. Metin A, Bulut O, Temizkan M. Relationship between the left spermatic vein diameter measured by ultrasound and palpated varicocele and Doppler ultrasound findings. Int Urol Nephrol. 1991;

8. Sakamoto H, Saito K, Shichizyo T, Ishikawa K, Igarashi A, Yoshida H. Color Doppler ultrasonography as a routine clinical examination in male infertility. Int J Urol. 2006;

9. Andrew Eskew L, Watson NE, Wolfman N, Bechtold R, Scharling E, Jarow JP. Ultrasonographic diagnosis of varicoceles. Fertil Steril. 1993;

10. Pilatz A, Altinkilic B, Köhler E, Marconi M, Weidner W. Color Doppler ultrasound imaging in varicoceles: Is the venous diameter sufficient for predicting clinical and subclinical varicocele? World J Urol. 2011;

11. Beddy P, Geoghegan T, Browne RF, Torreggiani WC. Testicular varicoceles. Clinical Radiology. 2005.

12. Braedel HU, Steffens J, Ziegler M, Polsky MS, Platt ML. A possible ontogenic etiology for idiopathic left varicocele. J Urol. 1994;

13. Yasim A, Resim S, Sahinkanat T, Eroglu E, Ari M, Efe E. Clinical and subclinical varicocele incidence in patients with primary varicose veins requiring surgery. Ann Vasc Surg. 2013;

14. Pfeifer S, Butts S, Catherino W, Davis O, Dumesic D, Fossum G, et al. Report on varicocele and infertility: A committee opinion. Fertil Steril. 2014;

15. Jungwirth A, Giwercman A, Tournaye H, Diemer T, Kopa Z, Dohle G, et al. European association of urology guidelines on male infertility: The 2012 update. European Urology. 2012.

16. Sharlip ID, Jarow J, Belker AM, Damewood M, Howards S, Lipshultz LI, et al. Report on varicocele and infertility: An AUA Best Practice Policy and ASRM Practice Committee Report. Fertil Steril. 2008;

17. Seo JT, Kim KT, Moon MH, Kim WT. The significance of microsurgical 
varicocelectomy in the treatment of subclinical varicocele. Fertil Steril. 2010;

18. Cantoro U, Polito M, Muzzonigro G. Reassessing the Role of Subclinical Varicocele in Infertile Men with Impaired Semen Quality: A Prospective Study. Urology. 2015;

19. Yamamoto M, Hibi H, Hirata Y, Miyake K, Ishigaki T. Effect of Varicocelectomy on Sperm Parameters and Pregnancy Rate in Patients with Subclinical Varicocele: A Randomized Prospective Controlled Study. J Urol. 1996 May;155(5):1636-8.

20. Butaney M, Thirumavalavan N, Hockenberry MS, Kirby EW, Pastuszak AW, Lipshultz LI. Variability in penile duplex ultrasound international practice patterns, technique, and interpretation: an anonymous survey of ISSM members. Int J Impot Res. 2018;

21. Butaney M, Thirumavalavan N, Rodriguez D, Gross MS, Munarriz R. Current practice in the management of ischemic priapism: an anonymous survey of ISSM members. Int J Impot Res. 2019; 
Figures and Tables

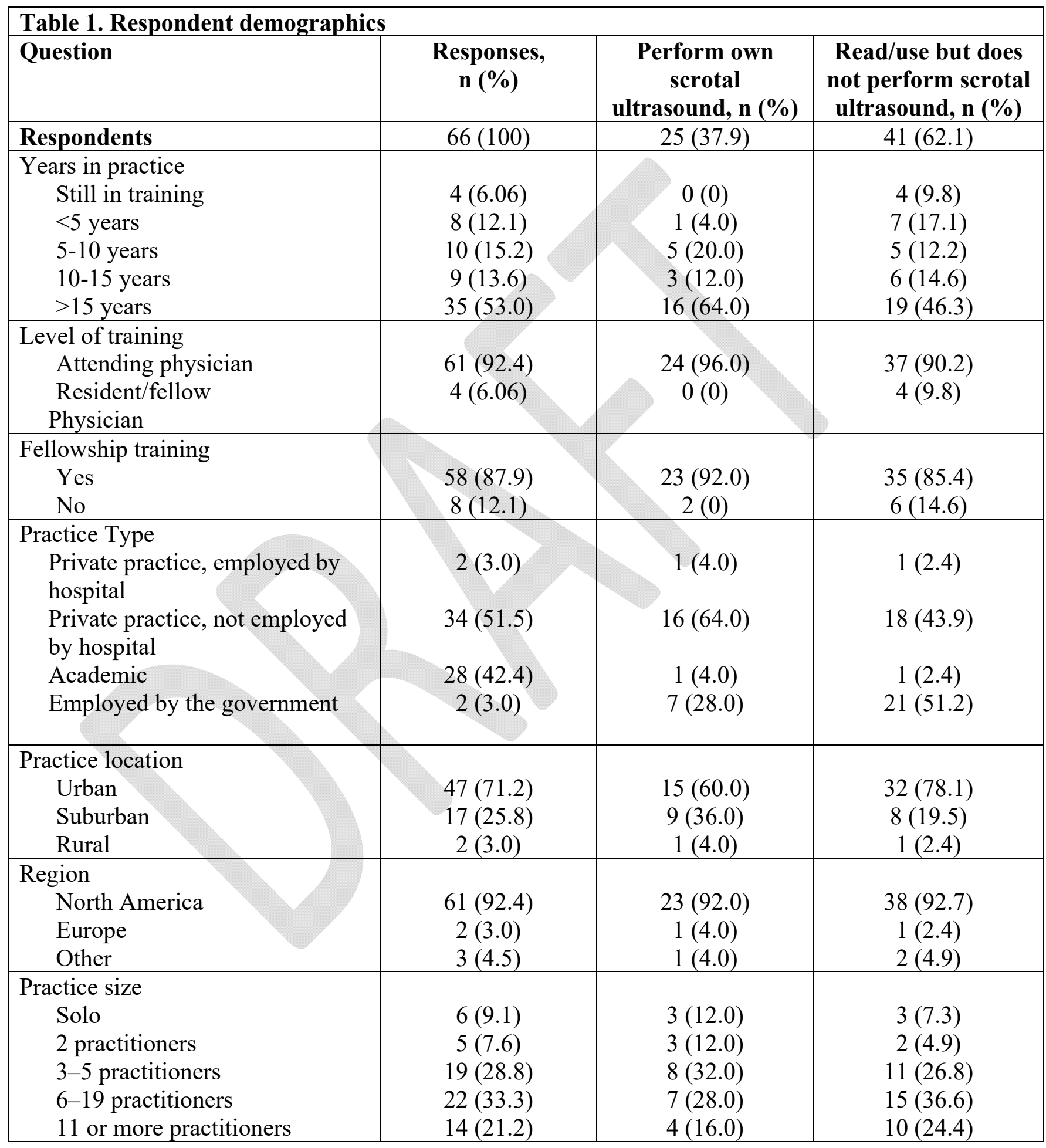




\begin{tabular}{|l|c|}
\hline \multicolumn{2}{|l|}{ Table 2. Variation in diameter based on respondent answers } \\
\hline Diameter & Respondents \\
\hline 2 & 5 \\
\hline 2.5 & 5 \\
\hline 3 & 26 \\
\hline 3.5 & 2 \\
\hline 4 & 3 \\
\hline $\mathrm{n} / \mathrm{a}$ & 8 \\
\hline$>2$ & 1 \\
\hline$>3$ & 2 \\
\hline $2.5-3 / 2-3$ & 4 \\
\hline 25 & 2 \\
\hline Other marked in blue & 5 \\
\hline TOTAL & 63 \\
\hline
\end{tabular}




\begin{tabular}{|l|c|c|}
\hline Table 3. Scrotal ultrasound technique and practice patterns \\
\hline Question & $\begin{array}{c}\text { Perform own } \\
\text { scrotal } \\
\text { ultrasound, } \\
\text { (\%) }\end{array}$ & $\begin{array}{c}\text { Read/use but does } \\
\text { not perform } \\
\text { scrotal } \\
\text { ultrasound, n (\%) }\end{array}$ \\
\hline Routinely look for varicoceles? & & \\
Yes & $22(88.0)$ & $34(89.5)$ \\
No & $3(12.0)$ & $2(5.3)$ \\
Unsure/do not know & 0 & $2(5.3)$ \\
\hline Position of ultrasound probe? & $1(4.0)$ & $1(2.6)$ \\
Inguinal & $21(88.0)$ & $25(65.8)$ \\
High scrotal & Other: $2(8.0)$ & $12(31.6)$ \\
Unsure/do not know & & \\
\hline Routinely measure venous diameter? & $21(84.0)$ & $28(73.7)$ \\
Yes & $4(16.0)$ & $6(15.8)$ \\
No & $0(0)$ & $4(10.5)$ \\
Unsure/do not know & & \\
& $10(40.0)$ & $14(36.8)$ \\
Position of patient? & $1(4.0)$ & $5(13.2)$ \\
Supine & $12(48.0)$ & $7(18.4)$ \\
Standing & $0(0)$ & $2(5.3)$ \\
Supine and standing (2 separate measurements) & $0(0)$ & $10(26.3)$ \\
Supine and standing (at the same time) & $2(8.0)$ & $0(0)$ \\
Unsure & $21(84.0)$ & $29(76.3)$ \\
Does not look for varicoceles & $4(16.0)$ & $9(23.7)$ \\
\hline Assess for retrograde flow in dilated veins? & & \\
Yes & $16(64.0)$ & $15(39.5)$ \\
No & $9(36.0)$ & $23(60.5)$ \\
\hline Is retrograde flow a requirement to make a & $24(96.0)$ & $36(94.7)$ \\
radiographic diagnosis of varicocele? & $1(4.0)$ & $2(5.3)$ \\
Yes & & \\
No & & \\
\hline Do patients Valsalva during measurements? & & \\
Yes & & \\
No & & \\
\hline
\end{tabular}




\begin{tabular}{|l|c|c|}
\hline Table 4. Indications for which respondent would fix varicocele \\
\hline Indication & $\begin{array}{c}\text { Palpable varicocele } \\
\text { discovered on physical exam, } \\
\mathbf{n}(\%)\end{array}$ & $\begin{array}{c}\text { Fix a subclinical/ } \\
\text { non-palpable varicocele } \\
\text { discovered on scrotal } \\
\text { ultrasound, n (\%) }\end{array}$ \\
\hline Pain & $48(78.7)$ & $12(19.6)$ \\
\hline Abnormal semen parameters & $60(98.4)$ & $26(42.6)$ \\
\hline Hypogonadism & $15(24.6)$ & $3(4.9)$ \\
\hline Cosmetics & $15(24.6)$ & $0(0)$ \\
\hline Idiopathic infertility & $25(41.0)$ & $13(21.3)$ \\
\hline $\begin{array}{l}\text { Testicular atrophy/smaller } \\
\text { testes size }\end{array}$ & $33(54.1)$ & $7(11.5)$ \\
\hline None of the above/never & $0(0)$ & $33(54.1)$ \\
\hline
\end{tabular}

